\title{
The Mediating Role of Green Practices in the Relationship between Effective Leadership Practices and Business Competitiveness
}

\author{
Ahmad Fathulla AHMAD iD a Georgiana KARADAS iD b Halgurd Fathulla AHMED iD c \\ a Aynda Private Technical Institute, Business Administration, Erbil, Iraq; ahmadfa-thulla.ciu@gmail.com \\ b Cyprus International University, Faculty of Economics and Administrative Sciences, Business Administration, Haspolat Campus, \\ Northern Cyprus; gkaradas@ciu.edu.tr \\ c Independent Researcher, Erbil, Iraq halgurd.ahmed@kbms.edu.krd
}

\begin{tabular}{ll}
\hline ARTICLE INFO & ABSTRACT \\
\hline Keywords: & $\begin{array}{l}\text { Purpose - This research examines the mediating roles of green supply chain management practices, } \\
\text { namely, green purchasing practices (GPP), green manufacturing practices (GMAP), green distribution/ } \\
\text { Leadership }\end{array}$ \\
$\begin{array}{l}\text { preen Practices } \\
\text { Sustainability }\end{array}$ & $\begin{array}{l}\text { effective leadership practices: leading organizational practice (LOP) and leading staff practice (LSP) } \\
\text { Business Competitiveness }\end{array}$ \\
and business competitiveness (BC).
\end{tabular}

Received 3 July 2021

Revised 1 October 2021

Accepted 1 November 2021

Design/methodology/approach - The research applied a quantitative approach, and a survey instrument was designed to collect empirical data from the Cihan group in Iraq. The data were analyzed by using partial least squares - structural equation modeling (PLS-SEM).

Findings - The results showed that LOP is significantly related to the green practices: GPP, GMAP, GDPP, and GMP. The research showed that LSP is positively associated with green supply chain practices: GPP, GMAP, GDPP, and GMP. The results also revealed the direct relationship between the same practices: GPP, GMAP, GDPP, and GMP with BC. The results showed that there was no significant correlation between LOP and BC. Meanwhile, LSP was positively and significantly related to BC.

Article Classification:

Research Article

Discussion - The research's findings revealed that all four practices of GSCM as GPP, GMAP, GDPP, and GMP, fully mediated the impact of LOP on BC since there was no significant direct relationship between LOP and BC. The research showed that green practices in the form of GPP, GMAP, GDPP, and GMP partially mediated the impact of LSP on BC, as the results showed a significant direct relationship between LSP and BC.

\section{Introduction}

Issues related to environmental pollution, waste of resources, and environmental disruption are becoming an increasingly global focus. Therefore, green practices in green supply chains have become a key strategic implementation to reduce environmental impact. This forces leaders to develop strategies to successfully meet up-coming challenges and grow (Ibrahim \& Daniel, 2019; Zhu \& Sarkis, 2004). The leadership theory indicated that effective leadership is a critical factor on which many activities in companies are based, thus leaders' most vital task is to shape individuals' behavior regarding the green concerns and ensure appropriate strategies (Hofmeyer, Brenda, Klopper \& Warland, 2015). The importance of green practices within green supply chain management (GSCM) for customers and the environment is realized when there is a decrease in the environmental impact and stocks by moving products directly to the place of purchase, on the basis that the GP has shown increased interest within the literature due to its effect on the various functions of organizations and companies, starting with the source of raw materials for the end consumer. This is owed to the fact that all materials, product parts, and the flow of information through supply chains also require reduced delivery deadlines, costs, and improved services (Zhu, Sarkis \& Geng, 2005). Business competitiveness creates value through high innovation that drives competition in the market because it represents assets that can achieve remarkable results. Therefore, most companies pursue to strengthen their sustainable competitive position in the market and pursue to provide outstanding products and services for 


\section{A. F. Ahmad - G. Karadas - H.F. Ahmed 13/4 (2021) 3498-3513}

growth, continuity, increased profits, and competitiveness in their overall performance (Prasetyo, Setyadharma \& Kistanti, 2020).

Therefore, this research explores the mediating roles of green practices such as green purchasing practices (GPP), green manufacturing practices (GMAP), green packaging (GDPP), and green marketing practices (GMP) in the correlation among leadership practices and business competitiveness. The mediating roles of green practices still require further examination in the literature (Keszey, 2020). This study aims to fill this research gap and considers the green practices' mechanism of mediation. In this regard, we empirically examined the mediating role of green practices in the relationship between effective leadership and business competitiveness to contribute further to the literature related to GSCM. The research also makes some original contributions to the effective leadership practices, GSCM practices, and business competitiveness literature. The research aims to provide theory-driven and empirically proven results that extend previous studies by demonstrating that leading staff practice (LSP) can directly and indirectly enhance business competitiveness (BC). However, leading organizational practice (LOP) can indirectly improve business competitiveness $(\mathrm{BC})$ through the mediating the role of green practices such as green purchasing practices (GPP), green manufacturing practices (GMAP), green distribution/ packaging practices (GDPP), and green marketing practices (GMP). Lastly, the theoretical research implications, and managerial implications of the findings will be discussed. The research is organized in five sections: in section two, the literature is reviewed; this section presents the conceptual model and hypotheses development. Section three comprises the research methodology. Section four contains the results. Finally, section five comprises discussions of the empirical findings, addresses theoretical and managerial implications, and includes limitations and suggestions for further research.

\section{Literature review}

\subsection{Effective leadership}

Effective leadership is the ability to stimulate the organization's staff to make daily decisions instinctively, increase the organization's potential in the future, and maintain its short-term stability. Hence, leaders can anticipate, predict, strengthen the versatile system and work as a team to initiate change within organizations. Leaders can influence managers and employees to think strategically and make decisions that benefit organizations (Atwater \& Carmeli, 2009). Leadership affects work satisfaction since employees need positive associations, a trustful environment, sustainable competitiveness, and decisive performance (Mastrangelo, Eddy \& Lorenzet, 2014). Therefore, one of the vital effective leadership roles is encouraging staff to participate collectively in organizational goals (Agarwal, Datta, Blake-Beard \& Bhargava, 2012). Leaders' self-esteem supports them in being honest about relationships and achieving transparency in relationships (Koohang, Paliszkiewicz, \& Gooluchowski, 2017). They are not expected to appear as selfpromoting information as leaders use approved self-control values (Kumar, 2014). Leaders who claim to be reliable tend to point to improved commitment, loyalty, and better performance (Walumbwa, Avolio, Gardner, Wernsing, \& Peterson, 2008). Consequently, effective leaders are vital to organizational success, as many researchers conclude. Effective leadership has an important role in managing the organization since leaders' experience and skills are capable of achieving the goals they pursue to reach (Asamoah, 2017). Effective leaders can find the appropriate relationship between organizations' demand and their most important concerns. Since leadership practices are essential components of organizations with high performance and high-quality products (Rehman, Sami, Haroon \& Irfan, 2019).

\subsection{Green practices}

Business competition emerged as a new model for economic development, particularly in the 1990s, when green practices improved significantly. This has therefore prompted companies to act responsibly ethically and socially in their supply chains. Competitiveness is also an issue of paramount importance to businesses and policymakers alike (Diabat \& Govindan, 2011). In this regard, green purchase is the first step of implementing green practices. Toke, Gupta, and Dandekar (2013) defined green purchasing as environmental purchasing that involves dropping, recycling, and reusing purchases. Green manufacturing practices are the renewal of production processes and are established environmentally friendly procedures, 


\section{A. F. Ahmad - G. Karadas - H.F. Ahmed 13/4 (2021) 3498-3513}

primarily in manufacturing. Green manufacturing is a vital step in green practices because it implements and prepares activities that require minimal energy and resource use in the industrial system and affect as little environmental pollution as possible (Gao, Li \& Song, 2009). As Abbas and Sagsan (2019) also indicated that there is a correlation between knowledge management processes, namely knowledge creation, acquisition, sharing, application and green technology, green management, green innovation, environment, social \& economic aspects of sustainability. The results show that knowledge management significantly impacts on green innovation and CSD activities. In addition to this, AlZgool and et. (2021) highlighted that green human resource management has major importance for food supply companies. Human Resource Management has a positive impact on promoting the performance of food supply companies in Bahrain. Therefore, green supply chain also plays a crucial contribution to the performance of food supply companies as well as COVID-19 also has a negative impact on firm performance.

The green distribution also comprises all activities that remove ecological damage and waste during transport, especially shipping, from the fuel-consuming transport cargo, the frequency of transport operations, until it reaches the customer, which affect the characteristics of packaging (weight, shape, and materials) on the performance of green distribution (Sarkis, 2003). Ottman, Stafford, and Hartman (2010) mentioned that green marketing is the process of developing, pricing, and promoting goods and services that do not harm the natural environment, as well as the process of designing, implementing, and monitoring the event, promoting, and distributing the product, establishing prices in a way that meets three essential criteria. According to Singh and Pandey (2012), marketing-supported green practice contains meeting human requirements with a minor adverse impact on the natural environment. Cost reduction is one of the most important benefits of managing the green supply chain in organizations that helps create a competitive advantage among organizations and increases customer purchasing power by lowering prices (AlNuaimi, Singh \& Harney, 2021).

\subsection{Business competitiveness}

Business competitiveness is the strategic weapon companies use to meet the market's challenges and competing companies to satisfy customers' needs. Competitiveness helps the business stay at the forefront, makes it operate, contributes to profitability, increases sales, and achieves growth and expansion (Macmillan \& Tampoe, 2001). Thus, competitiveness is an approach that makes it difficult to replace a business by its competitors and helps maintain profit margins. Thus, the company, to the extent possible, cannot be imitated or reproduced by other organizations. The company can preserve its competitive advantage since it is rich in market value resources (Chuang \& Huang, 2018).

According to Adams and Lamont (2003), competitiveness is the organization's ability to achieve the highest returns in the industry and maintain this progress. Marketing affects competitiveness, including consumer needs' determination, pricing, advertising, and promotion (Decyk, 2019). A company is competitive if it can produce goods and services of better quality, at lower costs than its domestic and international competitors, and has sufficient competitiveness to achieve long-term corporate profits, high performance, and the ability to compensate its employees with returns to its owners (Buckley, Pass \& Prescott, 2010). Competitiveness is transferred to different dimensions and to a wide field of business strategies because of the multiplicity of factors affecting the building and diversity of competitiveness. Business competitiveness is an issue of paramount importance to economists, businessmen, and economic policymakers alike (Wheelen \& Hunger, 2011). Competitiveness is therefore often measured in the relative value of competitors, market share, and profitability during a related period. Competitiveness also indicates the ability to perform better within the relevant market with good performance in various sectors at the country level. It's not just a market perspective but also a living and social factor (Famiyeh, Kwarteng, Asante-Darko \& Dadzie, 2018).

\subsection{Research model and hypotheses development}

As shown in Figure 1, the conceptual model for managing the empirical investigation is proposed. The model shows that the predictor variables are the leading organization practice (LOP) and leading staff practice (LSP), two main components of effective leadership practices. Based on the top executive theory, this research shows that effective leadership influences business competitiveness. In addition, the purpose of this research is also to investigate the mediating mechanism of green practices such as green purchasing practices (GPP), green manufacturing practices (GMAP), green distribution and packaging practices (GDPP), 
A. F. Ahmad - G. Karadas - H.F. Ahmed 13/4 (2021) 3498-3513

and green marketing practices (GMP), between the dimensions of effective leadership practices and business competitiveness (BC). Accordingly, the hypothesized interrelations are addressed hereafter between the research constructs.

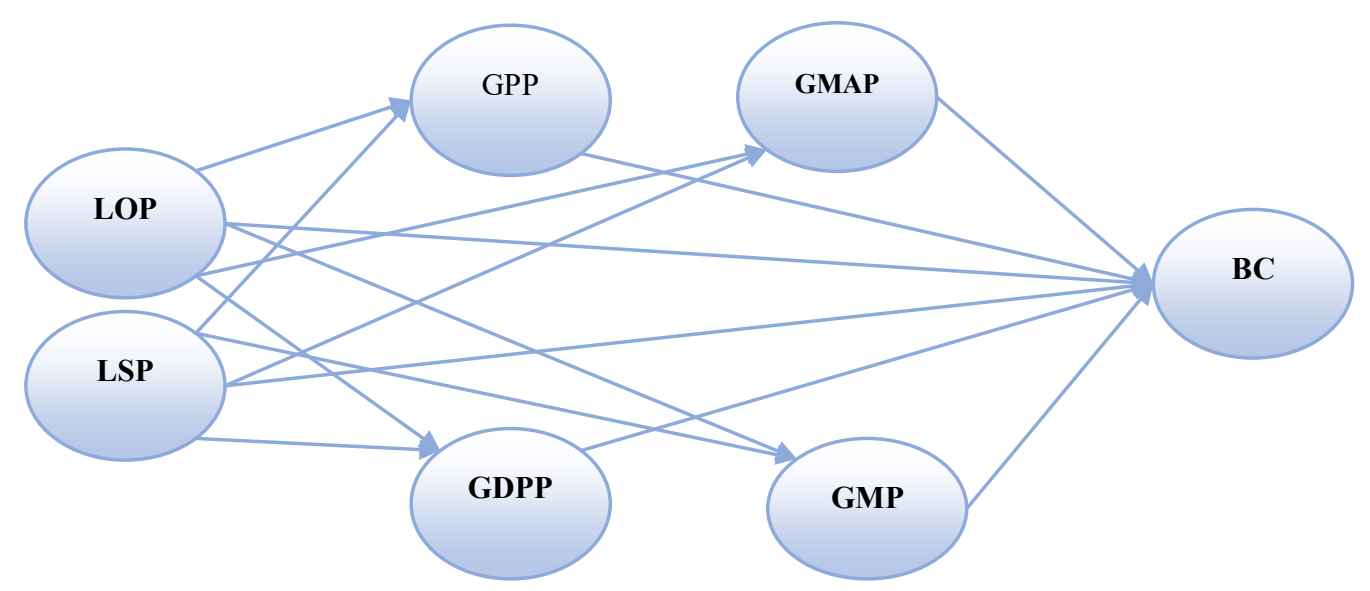

Fig. 1 Research conceptual model

Note: $\mathrm{LOP}=$ leading organization practice, $\mathrm{LSP}=$ leading staff practice, GPP = green purchasing practices, $\mathrm{GMAP}=$ green manufacturing practices, $\mathrm{GDPP}=$ green distribution and packaging practices, $\mathrm{GMP}=$ green marketing practices, and $\mathrm{BC}=$ business competitiveness.

\subsubsection{Relationship between effective leadership and green practices}

The top-management theory indicates that effective leadership practices are efficiently implemented by leading organizations and staff and are well thought out as the contributing influences of green consideration or implementing green practices in a company's green supply chain management. Related to leadership and green practices, Min and Galle (2001) explored the green purchasing practices of US firms. They showed that the company leadership's support is generally considered as a significant driver for green practices in the company's supply chain. Bessant, Kaplinsky, and Lamming (2003) investigated the role of leadership in green practices and showed a significant link between leadership practices and green purchasing practices (GPP), green manufacturing practices (GMAP), green distribution and packaging practices (GDPP), and green marketing practices (GMP). Gosling, Jia, Gong, and Brown (2016) examined the effective leadership's influence within the supply chain management (SCM) within sustainable practice learning. The results revealed that leadership has a significant role in green practices in sustainable supply chain management practices. Sharif and Irani (2012) showed that effective leadership is one the main factors of implementing green practices: GPP, GMAP, GDPP, and GMP, since effective leadership reflects a vital impact on many activities, including green practices in companies. Dubey, Gunasekaran, and Ali (2014) also showed a strong influence of leadership on implementing the green practices: GPP, GMAP, GDPP, and GMP. Therefore, the study proposed the following hypotheses:

Hypothesis 1 (H1): Leading organization practice is significantly related to (a) GPP, (b) GMAP, (c) GDPP, and (d) GMP

Hypothesis 2 (H2): Leading staff practice is significantly related to (a) GPP, (b) GMAP, (c) GDPP, and (d) GMP

\subsubsection{Green practices and business competitiveness}

Based on the resource-based view theory, the achievement of business competitiveness through the implementation of green practices, particularly in green human resources, promotes and maintains sustainable business practices, and environmental elements, which also supports the creation of awareness within the company regarding working in an environmentally sustainable manner. Thus, it links the gap between corporate activities and green practices, which includes environmentally friendly human resources practices (Ahmad, 2015). In Jordan's food industries, the research conducted by Diab, Al-Bourini, and Abu- 


\section{A. F. Ahmad - G. Karadas - H.F. Ahmed 13/4 (2021) 3498-3513}

Rumman (2015) presented the effect of green practices (GPP, GMAP, GDPP, and GMP) on organizational competitiveness and performance. In his research, Dahman (2012) discovered that green practices are the potential factors in enhancing performance and competitiveness. Lee, Kim, and Choi (2012) confirmed that green practices directly correlate with sustainable competitiveness. Villanueva, García, and Adame (2013) revealed that green practices as the green supply chain management components are the drivers of business competitiveness by bringing development and growth to companies. In Malaysia, the research conducted by Tan, Mohd, Tan, and Shaharudin (2016) showed that green practices are positively linked to competitiveness. Results also showed that both green manufacturing and green purchases directly influence the company's competitiveness. Top-management theory vital supports the following hypothesis:

Hypothesis 3 (H3): Green practices (a) GPP, (b) GMAP, (c) GDPP, and (d) GMP are positively and significantly related to business competitiveness.

\subsubsection{Effective leadership practices and business competitiveness}

Resource-based view theory (RBVT) points to the competitive advantages across the availability chain, such as the green supply chain (Gold, Seuring, \& Beske, 2010). In the Jordanian telecom research conducted by Al-Zureikat and Nour (2012), it is shown that effective leadership practices significantly impact the business competitiveness of Jordanian telecom. Gakure, Gichuhi, and Waititu (2014) revealed a significant positive association between organizational leadership and competitiveness; leadership also significantly influenced Kenyan public universities' competitiveness. Lastly, Uzcategui, Garcia, Garcia, Zaldumbide, and Solano (2018), in their research, discovered that effective leadership and the factors of business strategy have the most direct impact on competitiveness. Based on the above empirical results, we formulated our fourth hypothesis:

Hypothesis 4 (H4): Effective leadership (a) Leading organization practice, (b) leading staff practices positively and significantly affect business competitiveness.

\subsubsection{Green practices as a mediator}

Implementing green practices in companies' business activities is a contemporary topic. As green practices have become an important factor for industrial companies and service organizations as well around the world, there is an increasing need to apply green practices. Whereas the green practices can be important in facilitating a broad approach to achieve a culture of sustainability, which in turn mediates the success of a sustainable business competitiveness (AlNuaimi et al., 2021; Kahanaali, Khaksar \& Abbaslu, 2015; Rao \& Holt, 2005). Green practices are highly effective leadership sharing, particularly for companies seeking access to environmental and social performance, as vital components for improving competitiveness (Jain \& Sharma, 2014). Within a combined framework and effective approach, managers and effective leaders could develop and implement green practice initiatives, which involve customers to directly improve the environmental performance of suppliers, meaning that green practices mediate the impact of leadership and performance, primarily environmental performance (Kahanaali et al., 2015). Since the process of making products and services and organizing them from their origin as raw materials until they are ready for use by the customer requires several stages and this is what GSCM performs in practice (AlNuaimi et al., 2021). Chuang and Huang (2018) showed that green practices such as information technology capital mediates the effect of environmental corporate social responsibility on performance and business competitiveness. Based on their empirical results, Rao and Holt (2005) stated that the purpose of ecologically approachable means of shipping makes manufacturing firms reach environmental performance, economic performance, and competitiveness. As a result, it can be hypothesized that:

Hypothesis 5 (H5): GSCM practices: (a) GPP, (b) GMAP, (c) GDPP, and (d) GMP mediate the effect of Leading organization practice (LOP) on business competitiveness.

Hypothesis 6 (H6): GSCM practices: (a) GPP, (b) GMAP, (c) GDPP, and (d) GMP mediate the effect of Leading staff practice (LSP) on business competitiveness.

\section{Method}

A questionnaire survey was managed among all companies and branches of Cihan Group in Iraq, to test the research conceptual model, and its hypotheses, which were proposed based on specific theories. The current 


\section{A. F. Ahmad - G. Karadas - H.F. Ahmed 13/4 (2021) 3498-3513}

research aimed to explore the mediation mechanism of green practices in the relationship between effective leadership practices and business competitiveness (BC) with a data set from Iraq, particularly Cihan Group, a leading business within Iraq and the wider region. Furthermore, to achieve the research's main aim, the research was designed to assist the researchers in collecting data to test the variables. The research design also describes the sample's perceptions through the research population (Bryman \& Bell, 2015).

\subsection{Measures}

Seven constructs were defined to measure the research model and test the proposed hypotheses. The critical decision in conceptualizing and operationalizing the constructs is to determine whether the model's constructs are appropriate. In this context, Bell, Bryman, and Harley (2018) indicated that it was acceptable to use indicators or survey statements previously developed in the design of a new survey questionnaire, either by producing them or as inputs to support the design of new items. The items of effective leadership practices were adapted from the operating field from Koohang et al. (2017). The green practices constructs were measured as the collective green, or the eco-friendly business in the supply chain, such as green purchasing practices (GPP), green manufacturing practices (GMAP), green distribution and packaging practices (GDPP), green marketing practices (GMP) that were modified from Çankaya and Sezen (2019). Finally, for measuring the business competitiveness (BC) construct, nine items were modified from Chuang and Huang (2018). The questionnaire survey applied the following measurement scale: completely disagree as one and completely agree as seven.

\subsection{Research participators}

The research participators consist of managers and employees of several companies and levels working for the business holding called Cihan Iraq, where the group began its work in 1947 and laid the foundation stone for the group. The empirical data gathering was done via mailing out a letter of survey invitation to 622 potential respondents. Therefore, the surveys were processed by e-mail with an internet survey and were sent to the general managers, CEO, company managers, and employees in most Iraq regions. In the ending stage of the data acquiring, 389 completed questionnaires forms were obtained. Seven forms of the 389 were eliminated as they had misplaced data, therefore, yielding a final of 382 samples; hence the response rate was $61.41 \%$. Since the empirical data was also obtained from survey participators within two universities owned by the Cihan group, Ph.D. holders were $35.07 \%(n=134)$, participators who hold master's degree reached $33.2 \%(n=127)$, in addition to bachelor $20.6 \%(n=79)$; moreover, the degrees of bachelor diploma consisted of $10.9 \%(n=42)$. Managers who participated in the survey were $46.07 \%(n=176)$, most of them were CEOs, branch managers; general managers at top-level management, administrative staff and employees also participated $53.03 \%(n=206)$. The male participators reached $61.5 \%(n=235)$ and the rest were female participators (38.4\%; $n=147)$. Regarding the respondents' age, 36.3\% ( $n=139)$ were $41-50$ years old. Followed by $22.5 \%(n=86)$ respondents in the group of $51-60$ years, $20.2 \%(n=77)$ of the overall participators were between 31-40 years old. In addition, the group of 21-30 years old, had a rate of $17.8 \%(n=68)$, followed by the participators of 61 years and above, that is $3.2 \%(n=12)$.

\section{Results}

Empirical data were analyzed using the partial least squares (PLS) modeling based on the equation modeling technique. PLS is a modeling practice, which aims to exploit the descriptive variance of dependent constructs in a path model. Unlike other modeling techniques, PLS permits researchers to assess complex models that include many complex variables and indicators (Henseler \& Sarstedt, 2013). According to Chin, Peterson, and Brown (2008), the PLS analytical features assess research models with various constructs and their indicators, with a small and medium size of survey samples. In this context, Sarstedt, Ringle, and Hair (2017) revealed that PLS has three vital measurements for testing model constructs, as an important step, then testing hypotheses, namely validity, measurement model, and discriminant validity (correlation). In this regard, Hair, Hult, Ringle, and Sarstedt (2014) recommended that the values of the loadings for reliability and validity must greater than $>0.7$. The values of average variance extracted (AVE) related to convergent validity should be greater than $>0.50$. Additionally, the values of composite reliability (CR) must be greater than $>0.80$. For determining the internal reliability, the Cronbach's Alpha values must be greater or equal to 0.7 (Hair, Sarstedt, Pieper, \& Ringle, 2012). Besides, the average variance extracted (AVE) values of square roots' must be more than the correlation between the latent variables (Chin et al., 2008). 


\subsection{Evaluation of measurement model}

Results demonstrated that AVE values are between 0.565 and 0.702 , which are all greater than 0.05 . The values of CR related to constructs: LOP, LSP, GPP, GMAP, GDPP, GMP, and BC, are between 0.803 and 0.929 , which means that these constructs have values greater than $>0.80$. The results of Cronbach's $\alpha$ revealed that all values ranged from 0.807 to 0.942 , as they are higher than 0.70 indicating a good connection between the indicators of the model's constructs. Table 1 also demonstrated that the measurement model's values loaded ranging from 0.712 to 0.887 , which are greater than 0.70 . The assessment of the model's convergent validity was measured by Fornell-Larker criterion, based on this, we compared the values of average variance extracted (AVE) square roots of each model constructs that should be more than its relationships with all the other latent variables (Fornell \& Larcker, 1981), the scores loaded on square roots of AVE should be predictable in the correlation analysis matrix (Hair et al., 2012). As presented in Table 2, we established correlations or the discriminant validity by checking the AVE values of the root square, which should be more than related to another model's construct. As stated by vast researchers (Henseler, Ringle \& Sinkovics, 2009; McNeish, 2017; Tharenou, Donohue \& Cooper, 2007), it is essential to test and demonstrate the fit of the research model before testing the model hypotheses, and the indices of the model fit test should be within the recommended standards.

Table 1 Assessment of model measurement

\begin{tabular}{|c|c|c|c|c|c|}
\hline Constructs & Indicators & Loadings & AVE & $\mathrm{CR}$ & Cronbach's $\alpha$ \\
\hline \multirow{4}{*}{$\begin{array}{l}\text { Leading Organization } \\
\text { Practice }\end{array}$} & LOP1 & 0.778 & \multirow{4}{*}{0.651} & & \multirow{4}{*}{0.807} \\
\hline & LOP2 & 0.839 & & \multirow{3}{*}{0.875} & \\
\hline & LOP3 & 0.837 & & & \\
\hline & LOP4 & 0.823 & & & \\
\hline \multirow{6}{*}{ Leading Staff Practice } & LSP1 & 0.718 & \multirow{6}{*}{0.663} & \multirow{6}{*}{0.887} & \multirow{6}{*}{0.843} \\
\hline & LSP2 & 0.778 & & & \\
\hline & LSP3 & 0.748 & & & \\
\hline & LSP4 & 0.786 & & & \\
\hline & LSP5 & 0.729 & & & \\
\hline & LSP6 & 0.778 & & & \\
\hline \multirow{4}{*}{$\begin{array}{l}\text { Green Purchasing } \\
\text { Practices }\end{array}$} & GPP1 & 0.737 & \multirow{4}{*}{0.619} & \multirow{4}{*}{0.892} & \multirow{4}{*}{0.849} \\
\hline & GPP2 & 0.798 & & & \\
\hline & GPP3 & 0.769 & & & \\
\hline & GPP4 & 0.835 & & & \\
\hline \multirow{3}{*}{$\begin{array}{l}\text { Green Manufacturing } \\
\text { Practices }\end{array}$} & GMAP1 & 0.768 & \multirow{3}{*}{0.702} & \multirow{3}{*}{0.929} & \multirow{3}{*}{0.942} \\
\hline & GMAP2 & 0.767 & & & \\
\hline & GMAP3 & 0.823 & & & \\
\hline \multirow{4}{*}{$\begin{array}{l}\text { Green Distribution and } \\
\text { Packaging Practices }\end{array}$} & GDPP1 & 0.749 & \multirow{4}{*}{0.638} & \multirow{4}{*}{0.884} & \multirow{4}{*}{0.841} \\
\hline & GDPP2 & 0.887 & & & \\
\hline & GDPP3 & 0.786 & & & \\
\hline & GDPP4 & 0.779 & & & \\
\hline \multirow{6}{*}{$\begin{array}{l}\text { Green Marketing } \\
\text { Practices }\end{array}$} & GMP1 & 0.769 & \multirow{6}{*}{0.638} & \multirow{6}{*}{0.865} & \multirow{6}{*}{0.817} \\
\hline & GMP2 & 0.732 & & & \\
\hline & GMP3 & 0.809 & & & \\
\hline & GMP4 & 0.755 & & & \\
\hline & GMP5 & 0.863 & & & \\
\hline & GMP6 & 0.757 & & & \\
\hline \multirow{9}{*}{ Business Competitiveness } & $B C 1$ & 0.708 & \multirow{9}{*}{0.565} & \multirow{9}{*}{0.803} & \multirow{9}{*}{0.879} \\
\hline & $B C 2$ & 0.799 & & & \\
\hline & $B C 3$ & 0.855 & & & \\
\hline & $B C 4$ & 0.847 & & & \\
\hline & BC5 & 0.719 & & & \\
\hline & $B C 6$ & 0.882 & & & \\
\hline & $B C 7$ & 0.712 & & & \\
\hline & $B C 8$ & 0.715 & & & \\
\hline & $B C 9$ & 0.746 & & & \\
\hline
\end{tabular}


A. F. Ahmad - G. Karadas - H.F. Ahmed 13/4 (2021) 3498-3513

Table 2 Assessment of discriminant validity

\begin{tabular}{cllccccc}
\hline \multicolumn{7}{c}{ Fornell-Larker Criterion } \\
\hline Constructs & LOP & LSP & GPP & GMAP & GDPP & GMP & BC \\
\hline LOP & 0.834 & & & & & & \\
LSP & 0.769 & 0.811 & & & & & \\
GPP & 0.660 & 0.747 & 0.781 & & & & \\
GMAP & 0.547 & 0.631 & 0.730 & 0.807 & & & \\
GDPP & 0.677 & 0.702 & 0.745 & 0.678 & 0.786 & & \\
GMP & 0.809 & 0.789 & 0.773 & 0.800 & 0.758 & 0.897 & \\
BC & 0.600 & 0.636 & 0.731 & 0.698 & 0.600 & 0.699 & 0.884 \\
\hline
\end{tabular}

Note: $\mathrm{LOP}=$ leading organization practice, $\mathrm{LSP}=$ leading staff practice, GPP = green purchasing practices, GMAP = green manufacturing practices, $\mathrm{GDPP}=$ green distribution and packaging practices, $\mathrm{GMP}=$ green marketing practices, and $\mathrm{BC}=$ business competitiveness.

As Table 3 demonstrates, the SRMR value is 0.0720 , less than the recommended standards $(0.08)$, and indicating a good fit. In addition to the value of Chi-square, for research models with about 200 cases, the Chi-square test is generally a reasonable measure of fit. However, for the models with a greater number, for instance (400 or more), Chi-square is always statistically significant, which means it is suitable for our model. The results showed that Chi-square reached 1.786 which is less than (3.0), therefore, revealing a good index and fit, where this test assesses whether variables are associated, and the results are accurate. The value of NFI is also in the recommended standards; as it is more than 0.90 and nearer to 1 , this can be interpreted as a good value. Moreover, the values of the Variance Inflation Factor (VIF) of all indicators of the research model reached from 1.000 to 1.828 and all were less than $<5$, based on these results, we can establish the model fit and consider having a good fit. Based on the results of all model fit indexes, we can proceed to test the model, which is suitable to run the statistical analysis and test the hypotheses.

Table 3 Model Fit Test

\begin{tabular}{lccc}
\hline Fitness Test Method & Estimated Model & Decision criteria & $\begin{array}{c}\text { Overall } \\
\text { Decision }\end{array}$ \\
\hline SRMR & 0.0720 & $<0.08$ & Fit \\
$\chi 2$ & 1.786 & $\leq 3.0$ & Fit \\
NFI & 1.000 & $\geq 0.90$ & Fit \\
VIF & Ranged from 1.000 to 1.828 & $<5$ & Fit \\
\hline
\end{tabular}

Note: $\mathrm{SRMR}=$ Standardized Root-Mean-Square Residual, $\chi 2=$ chi-square, NFI = Normed Fit Index, and VIF= Variance Inflation Factor.

\subsection{Hypotheses testing}

The values of R2 determine the prediction of the research model, and the values should be at a minimum value of 0.10, which is acceptable (Elliott \&Woodward, 2007; Hair et al., 2012). Figure 2 shows that the values of R2 for GPP, GMAP, GDPP, GMP, and BC are 0.278, 0.285, 0.353, 0.289, and 0.350, respectively; these results confirmed that the values loaded on model's R2 could determine a meaningful explanation of the data and analysis results. This is reached through the coefficients of path analysis, $t$-values, and $p$-values for defining the hypotheses' acceptance or rejection which are displayed in Table 4, and the results showed that LOP is positively and significantly related to green purchasing practices (GPP), green manufacturing practices (GMAP), green distribution and packaging practices (GDPP), and green marketing practices (GMP) with the coefficients effects of $0.422,0.430,0.317$, and 0.450 , with p-values less than 0.05 , which are all significant; therefore, H1a, H1b, H1c, and H1d are confirmed. 

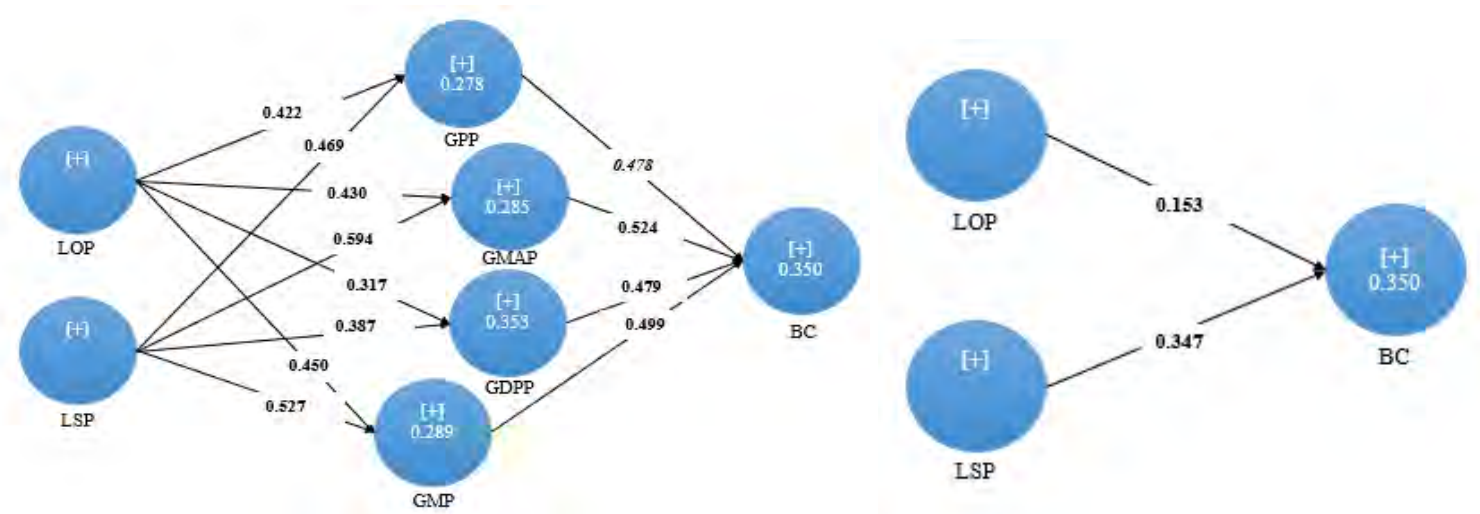

Fig.2 Path diagram for structural equation modeling results

The results also indicated that LSP is positively and significantly related to green practices as GPP, GMAP, GDPP, and GMP with the coefficients effects 0.469, 0.594, 0.387, and 0.527, with p-values less than 0.05, all significant, hence, $\mathrm{H} 2 \mathrm{a}, \mathrm{H} 2 \mathrm{~b}, \mathrm{H} 2 \mathrm{c}$, and $\mathrm{H} 2 \mathrm{~d}$ find support. The results showed that green practices GPP, GMAP, GDPP, and GMP influenced BC, with coefficients up to 0.478, 0.524, 0.479, and 0.499, with p-values $=0.000$, all less than 0.05 , hence significant. Therefore, H3a, H3b, H3c, and H3d are also confirmed. Further, LOP is related to BC; however, the relationship is not significant, (coefficient $=0.245$, $p$-value $=0.059$, which is greater than 0.05), that is there was no significant direct relationship between LOP and BC; thus, H4a is rejected. In contrast, LSP is significantly related to $B C$ (coefficient $=0.347, p=0.000$, which is less than 0.05); accordingly, $\mathrm{H} 4 \mathrm{~b}$ is accepted. As revealed in Table 5, effective leadership practices LOP and LSP were the independent variables, green practices GPP, GMAP, GDPP, and GMP were the mediating variables, and BC was the dependent variable. As Table 5 shows, the direct effect values of LOP and LSP on BC were recorded in the mediator's absence $(\beta=0.153$, and $\beta=0.347),(p=0.059$, and 0.000$)$. The indirect effects were noted with the mediator's inclusion and the coefficients effects $0.207,0.225,0.152$, and 0.224 , with the p-values $=0.007$, $0.005,0.045$, and 0.005 . These results show that the green practices GPP, GMAP, GDPP, and GMP fully mediated the effect of LOP on BC. Thus, $\mathrm{H} 5 \mathrm{a}, \mathrm{H} 5 \mathrm{~b}, \mathrm{H} 5 \mathrm{c}$, and $\mathrm{H} 5 \mathrm{~d}$ are accepted showing that green practices: GPP, GMAP, GDPP, and GMP mediate the effect of LOP on BC. The results in Table 5 showed the indirect effect of green practices: GPP, GMAP, GDPP, and GMP in the relationship between LSP and BC, with the coefficients of $0.224,0.311,0.185$, and 0.263 , and the level of significance ( $p=0.005,0.000,0.023$, and 0.001). Accordingly, H6a, H6b, H6c, and H6d are accepted. The results also established that green practices: GPP, GMAP, GDPP, and GMP partially mediated the effect of LSP on SBC.

Table 4 Path analysis coefficient, t-value, and p-value for the SEM

\begin{tabular}{|c|c|c|c|c|c|}
\hline Hypotheses & Interaction & $\begin{array}{c}\text { Standardized Path } \\
\text { Coefficient }\end{array}$ & $t$-value & $p$-value & Decision \\
\hline$H 1 a$ & LOP $->$ GPP & $\beta=0.422$ & 7.676 & 0.000 & Supported \\
\hline$H 1 b$ & LOP -> GMAP & $\beta=0.430$ & 7.854 & 0.000 & Supported \\
\hline$H 1 c$ & LOP $->$ GDPP & $\beta=0.317$ & 5.506 & 0.003 & Supported \\
\hline H1d & LOP -> GMP & $\beta=0.450$ & 8.318 & 0.000 & Supported \\
\hline$H 2 a$ & LSP -> GPP & $\beta=0.469$ & 8.765 & 0.000 & Supported \\
\hline$H 2 b$ & LSP -> GMAP & $\beta=0.594$ & 12.184 & 0.000 & Supported \\
\hline$H 2 c$ & LSP -> GDPP & $\beta=0.387$ & 6.930 & 0.000 & Supported \\
\hline$H 2 d$ & LSP -> GMP & $\beta=0.527$ & 10.223 & 0.000 & Supported \\
\hline H3a & GPP -> BC & $\beta=0.478$ & 8.865 & 0.000 & Supported \\
\hline$H 3 b$ & GMAP $->$ BC & $\beta=0.524$ & 10.116 & 0.000 & Supported \\
\hline$H 3 c$ & GDPP $\rightarrow$ BC & $\beta=0.479$ & 8.870 & 0.000 & Supported \\
\hline$H 3 d$ & GMP $\rightarrow$ BC & $\beta=0.499$ & 9.523 & 0.000 & Supported \\
\hline$H 4 a$ & LOP $>$ BC & $\beta=0.153$ & 1.897 & 0.059 & Not supported \\
\hline$H 4 b$ & LSP $\rightarrow$ BC & $\beta=0.347$ & 4.318 & 0.000 & Supported \\
\hline
\end{tabular}


Table 5 Mediating analysis

\begin{tabular}{|c|c|c|c|}
\hline Hypothesis & Interaction & Indirect Beta w/Med & Mediation Type Observed \\
\hline H5a & LOP $->$ GPP $->$ BC & $\beta=0.207, p=0.007$ & Full mediation \\
\hline$H 5 b$ & LOP $->$ GMAP $->$ BC & $\beta=0.225, p=0.005$ & Full mediation \\
\hline $\mathrm{H} 5 \mathrm{c}$ & LOP $->$ GDPP $->$ BC & $\beta=0.152, p=0.045$ & Full mediation \\
\hline$H 5 d$ & LOP $->$ GMP $->B C$ & $\beta=0.224, p=0.005$ & Full mediation \\
\hline H6a & LSP $->$ GPP $->$ BC & $\beta=0.224, p=0.005$ & Partial mediation \\
\hline H6b & LSP $->$ GMAP $->$ BC & $\beta=0.311, p=0.000$ & Partial mediation \\
\hline H6c & LSP $->$ GDPP $->$ BC & $\beta=0.185, p=0.023$ & Partial mediation \\
\hline H6d & LSP $>$ GMP $>$ BC & $\beta=0.263, p=0.001$ & Partial mediation \\
\hline
\end{tabular}

Note: $\mathrm{LOP}=$ leading organization practice, LSP = leading staff practice, GPP = green purchasing practices, $\mathrm{GMAP}=$ green manufacturing practices, $\mathrm{GDPP}=$ green distribution and packaging practices, $\mathrm{GMP}=$ green marketing practices, and $\mathrm{BC}=$ business competitiveness.

\section{Discussion and conclusions}

The ultimate purpose of this research was to explore the mediating role of green practices, namely, green purchasing practices, green manufacturing practices, green distribution, and packaging practices, and green marketing practices, in the relationship between effective leadership practices as leading organization practice (LOP), leading staff practice (LSP), and business competitiveness. The proposed research model was tested with empirical data obtained from respondents in the Cihan group in Iraq. The results showed that effective leadership practices positively and significantly correlate with green practices such as green purchasing practices, green manufacturing practices, green distribution, packaging practices, and green marketing practices. The significance of green practices in manufacturing companies was highlighted by Madu, Kuei, and Madu (2012) who mentioned that the increasing environmentally friendly concerns within green practices have gradually become part of the organizational culture, supporting the re-engineering of the organization's strategies, and improving business competitiveness. Through green practices, companies also could enhance their corporate image, enhance their market dominance, and enter a new market, which may eventually increase their financial performance (Carter, Kale, \& Grimn, 2000). The research established that green practices are positively and significantly related to business competitiveness.

The research's findings revealed that all four practices of GSCM: green purchasing practices (GPP), green manufacturing practices (GMAP), green distribution/ packaging practices (GDPP), and green marketing practices (GMP) fully mediated the impact of leading organization practice (LOP) on business competitiveness (BC) since there was no significant direct relationship between LOP and BC. In addition, the research showed that the green practices: GPP, GMAP, GDPP, and GMP partially mediated the impact of leading staff practice (LSP) on business competitiveness (BC). The results showed a significant direct relationship between LSP and BC. Green practices reduce the environmental impact of the supply chain front and reverse the movements while generating economic values and lowering costs (Vachon \& Klassen, 2008). The research's results align with previous researchers (Bessant et al., 2003; Gosling et al., 2016), whose findings showed that effective leadership affects the implementation of green practices in supply chains. Typically, green practices consist of actions that eliminate pollution, reduce waste, remove harmful substances, consider product life cycles, evaluate resources particularly for environmental performance, highlight compliance, and further reduce the operations' environmental impact. In this context, the evidence confirmed that companies had implemented the GSCM system, which improved performance (Handfield, Sroufe, \& Walton, 2005; Zhu \& Sarkis, 2004). For instance, companies can reduce noise pollution by implementing green manufacturing practices and replacing contaminated and hazardous materials/ parts. Through green manufacturing practices, companies also control emissions, and discharge. The design of the process also focuses on reducing energy and natural resource consumption in operations.

\subsection{Theoretical implications}

The current research is unique and contributes to the literature since there is a lack of published studies on effective leadership practices, green practices, and business competitiveness. The research provides unique information regarding the significance of green practices in the relationship between leadership and competitiveness. Effective leadership comes due to perseverance in learning and development, successful 


\section{A. F. Ahmad - G. Karadas - H.F. Ahmed 13/4 (2021) 3498-3513}

experiences, and sound practice, in addition to leadership qualities, talents, and personal qualities. Few previous studies examined the impact of green practices in GSCM on business competitiveness (Diab et al., 2015; Tan et al., 2016; Villanueva et al., 2013). Yet, our research differs from previous studies as the main components GSCM, or green practices are explored as a mediator mechanism between two effective leadership practices and business competitiveness. The role of mediation of green practices remains primarily not investigated in the literature, which consititued a research gap (Bu, Dang, Wang, \& Liu, 2020; Keszey, 2020). As a result, the research's contribution is significant. In this regard, Aslam Waseem and Khurram (2019) recommended future studies to test a broader model on the importance of green practices in developing countries through the containment of competitiveness. Ahmed, Ahmed, and Najmi (2018) recommended that future research may empirically examine more green practices, to test their effects on cognitive results to contribute more largely to green practices literature and provide in-depth information on green practices.

\subsection{Managerial implications}

This research has significant management implications for managers and leaders within all companies and business branches of the Cihan Group, where the study showed that effective leadership through the mediation mechanism of green practices improves competitiveness. A key recommendation is that training Cihan group staff on green issues should be a top strategic priority for employees to effectively implement green practices in the group's supply chains, which have a significant impact on business competitiveness. Thus, the group leaders and managers should realize that green initiatives improve their companies to find alternative ways to cut costs without losing their best talent. In this regard, the Cihan group can focus on green human resource practices as a strategic initiative that promotes sustainable business practices. Consequently, it required developing a new organizational culture through green practices, which becomes a concern for managers. Developing a green culture can influence employee behavior and deliver certain values that build an internal culture.

Leaders' green concern is vital at all organization levels; green practices include environmentally friendly HR initiatives that lead to greater efficiency, lower costs, better employee engagement, and retention, based on that leaders' influence can reach the favorite outcomes (Kuria, Namusonge, \& Iravo, 2016). Leaders in the manufacturing industries, including the Cihan group, can effectively improve their competitiveness by implementing green practices (Gosling et al., 2016), as leadership is the improvement factor of many actions, particularly communications, that can promote such green practices. Leaders can inspire the staff to attain the company's goals. In this context, green practices are an active and environmentally friendly approach for companies to gain sustainable competitiveness (Bu et al., 2020; Chan, 2010). In addition, Cihan group's companies need to conduct environmental audits, thereby changing the organizational culture, thinking further about waste management, pollution, and helping the community and its members, who are affected by pollution. It can also make staff and community members more aware of the economic use of natural resources and encourage environmentally friendly products. Besides, leaders at Cihan group should improve sustainable competitiveness for their group companies. It can support the elimination of the most critical obstacles in order to improve efficiency and productivity, namely the domestic market problem, which can benefit from the considerable size availability. Therefore, reaching a competitive environment ensures economic efficiency and living standards (Hussain, Mu, Mohiuddin, Danish, \& Sair, 2020).

\subsection{Limitations and suggestions for future research}

This research may not be without limitations, as the data were obtained during Covid-19, which affected our abilities to obtain a large samples size. First, for reducing common method bias (CMB) that may affect statistical testing, we have followed several possible ways to prevent pressing CMB issues related to surveybased data, that is, we have obtained data from managers and employees. As mentioned, Coronavirus limited our abilities to survey all manufacturing companies in Iraq. Hence, in future research, hypotheses can be tested using larger data, including empirical data from many manufacturing companies, which may present better results for reducing $\mathrm{CMB}$. The results may also be examined in a wider context by expanding the survey samples and supporting the generalization of the findings. Second, we built our theoretical framework based on theories related to top management and the resource-based view theory due to their relevance to green practices and competitiveness. The hypotheses were based and focused on green practices namely, green purchasing practices (GPP), green manufacturing practices (GMAP), green 
A. F. Ahmad - G. Karadas - H.F. Ahmed 13/4 (2021) 3498-3513

distribution/ packaging practices (GDPP), and green marketing practices (GMP) and competitiveness in line with the organizational theory lens. We suggest future research to test green practices in manufacturing and service companies as mediators between other relevant relationships too. The concern of implementing green practices in the supply chain is the circle that begins and ends with the customer, as all materials, products, information, and transactions flow through this circle, and it is also a facility for all businesses with different and competitive goals. Furthermore, future research could provide attention to a diverse and larger sample, including many industrial companies.

\section{Acknowledgements}

The authors thank the Cihan Group in Iraq for participating in the survey and support the research.

\section{References}

Abbas, J., \& Sağsan, M. (2019). Impact of knowledge management practices on green innovation and corporate sustainable development: A structural analysis. Journal of Cleaner Production, 229, 611-620.

Adams, G. L., \& Lamont, B. T. (2003). Knowledge management systems and developing a sustainable competitive advantage. Journal of Knowledge Management, 7, 142-154.

Agarwal, U. A., Datta, S., Blake-Beard, S., \& Bhargava, S. (2012). Linking LMX, innovative work behavior, and turnover intentions: The mediating role of work engagement. Career Development International, 17, 208-230.

Ahmed, W., Ahmed, W., \& Najmi, A. (2018). Developing and analyzing framework for understanding the effects of GSCM on green and economic performance; a perspective of a developing country. Management of Environmental Quality, 29, 740-758.

Ahmad, S. (2015). Green human resource management: Policies and practices. Cogent Business $\mathcal{E}$ Management, 2(1), 1-13.

AlZgool, M., Ahmed, U., Shah, S., Alkadash, T., \& AlMaamary, Q. (2021). Going green during COVID-19: Examining the links between green HRM, green supply chain and firm performance in food Industry of Bahrain: The moderating role of lockdown due to COVID-19. Uncertain Supply Chain Management, 9(1), 79-88.

AlNuaimi, B. K., Singh, S. K., \& Harney, B. (2021). Unpacking the role of innovation capability: Exploring the impact of leadership style on green procurement via a natural resource-based perspective. Journal of Business Research, 134, 78-88.

Al-Zureikat, K. K. S., \& Nour, M. I. (2012). The impact of transformational leadership in achieving business competitiveness advantage: An empirical study in Jordan telecom group. Baghdad College of Economic Sciences Journal, 33, 1-40.

Asamoah, J. K. (2017). The impact of effective leadership practice on organizational performance and growth of state-owned banks in Ghana. Review of Public Administration and Management, 5(3), 1-8.

Aslam, H., Waseem, M., Khurram, M. (2019). Impact of green supply chain management practices on corporate image: the mediating role of green communications. Pakistan Journal of Commerce and Social Sciences, 13, 581-598.

Atwater, L., \& Carmeli, A. (2009). Leader-member exchange, feelings of energy, and creative work involvement. The Leadership Quarterly, 20, 264-275.

Bell, E., Bryman, A., \& Harley, B. (2018). Business research methods. Oxford University Press. 


\section{A. F. Ahmad - G. Karadas - H.F. Ahmed 13/4 (2021) 3498-3513}

Bessant, J., Kaplinsky, R., \& Lamming, R. (2003). Putting supply chain learning into practice, International Journal of Operations and Production Management, 23, 167-184.

Bryman, A., \& Bell, E. (2015). Business research methods; Bell \& Bain Ltd.: Glasgow, the UK.

Bu, X., Dang, W. V. T., Wang, J., \& Liu, Q. (2020). Environmental orientation, green supply chain management, and firm performance: empirical evidence from Chinese small and medium-sized enterprises. Int. J. Environ Res Public Health. 17, 1199.

Buckley, P., Pass, C., \& Prescott, K. (2010). Measures of international competitiveness: A critical survey. Journal of Marketing Management, 4, 175-200.

Carter, C.R., Kale, R., \& Grimn, C.M. (2000). Environmental purchasing and firm performance: an empirical investigation. Transportation Research Part E, 36, 219-88.

Çankaya, S. Y., \& Sezen, B. (2019). Effects of green supply chain management practices on sustainability performance. Journal of Manufacturing Technology Management, 30, 98-121.

Chan, R. Y. K. (2010). Corporate environmentalism pursuit by foreign firms competing in China. J. World Bus. 45, 80-92. doi: 10.1016/j.jwb.2009.04.010.

Chin, W. W., Peterson, R. A., \& Brown, S. P. (2008). Structural equation modeling in marketing: Some practical reminders. Review of the Journal of Marketing Theory and Practice, 16, 287-98.

Chuang, S., \& Huang, S. (2018). The effect of environmental corporate social responsibility on performance and business competitiveness: the mediation of green information technology capital. Journal of Business Ethics, 150, 991-1009.

Cihan Group, (2020). A brief history of the Cihan Group and major activities, available online https://www.cihan.com/en/about-us [accessed April 11, 2020].

Dahman, T. (2012). The impact of supply chain management no organizational performance: A field study in Kuwaiti industrial companies listed in Kuwait Stock Exchange. (Unpublished Master Thesis). Business Administration, Middle East University.

Decyk, K. (2019). Competitiveness factors in innovative enterprises. Proceedings of 6th International Scientific Conference on Contemporary Issues in Business, Management and Economics Engineering. doi:10.3846/cibmee.2019.055.

Diab, S. M., Al-Bourini, F. A., \& Abu-Rumman, A. H. (2015). The impact of green supply chain management practices on organizational performance and business competitiveness: a study of Jordanian food industries. Journal of Management and Sustainability, 5, 149-157.

Diabat, A., \& Govindan, K. (2011). An analysis of the Drivers Affecting the Implementation of Green Supply Chain Management. Resources, Conservation, and Recycling, 55, 659-666.

Dubey, R., Gunasekaran, A., \& Ali, S. S. (2014). Exploring the relationship between leadership, operational practices, institutional pressures, and environmental performance: A framework for the green supply chain. International Journal of Production Economics, Elsevier, 160, 120-132.

Elliott, A. C., \& Woodward, W. A. (2007). Statistical Analysis Quick Reference Guidebook: With SPSS Examples, Sage, Thousand Oaks.

Famiyeh, S., Kwarteng, A., Asante-Darko, D., \& Dadzie, S. A. (2018). Green supply chain management initiatives and competitive operational performance. Benchmarking: An International Journal, 25, 607-631.

Fornell, C., \& Larcker, D. F. (1981). Evaluating structural equation models with unobservable variables and measurement error. Journal of Marketing Research, 18, 39-50.

Gakure, R. W., Gichuhi, D. M., \& Waititu, A. G. (2014) Influence of organizational leadership on the competitiveness of public universities in Kenya, IOSR Journal of Humanities and Social Science (IOSRJHSS), 19, 13-19. 


\section{A. F. Ahmad - G. Karadas - H.F. Ahmed 13/4 (2021) 3498-3513}

Gao, Y., Li, J., \& Song, Y. (2009). Performance Evaluation of Green Supply Chain Management Based on Membership Conversion Algorithm. ISECS International Colloquium on Computing, Communication, Control, and Management, IEEE, Sanya, 237-240.

Gold, S., Seuring, S., \& Beske, P. (2010). Sustainable supply chain management and inter-organizational resources: a literature review. Corporate social responsibility and environmental management, 17(4), 230-245.

Gosling, J., Jia, F., Gong, Y., \& Brown, S. (2016). The role of supply chain leadership in the learning of sustainable practice: toward an integrated framework, Journal of Cleaner Production, 137, 1458-1469.

Hair, J. F., Sarstedt, M., Pieper, T. M., \& Ringle, C. M. (2012). The use of partial least squares structural equation modeling (PLS-SEM) in strategic management research: A review of past practices and future applications recommendations. Long Range Planning, 45, 320-340.

Hair, J., Hult, G., Ringle, C., \& Sarstedt, M. (2014). A primer on partial least squares structural equation modeling (PLS-SEM). Thousand Oaks, CA: Sage Publications.

Handfield, R., Sroufe, R., \& Walton, S. (2005). Integrating environmental management and supply chain strategies. Business Strategy and the Environment, 14, 1-19.

Henseler, J., \& Sarstedt, M. (2013). Goodness-of-fit indices for partial least squares (PLS), path modeling, Computational Statistics, 28, 565-580.

Henseler, J., Ringle, C. M., \& Sinkovics, R. R. (2009). The use of partial least squares (PLS) path modeling in international marketing. Advances in International Marketing (AIM), 20, 277-320.

Hofmeyer, A., Brenda, H. S., Klopper, H. C., \& Warland, J. (2015). Leadership in learning and teaching in higher education: perspectives of academics in non-formal leadership roles. Contemporary Issues in Education Research (Online), 8, 181-192.

Hussain, I., Mu, S., Mohiuddin, M., Danish, R. Q., \& Sair, S. A. (2020). Effects of sustainable brand equity and marketing innovation on market performance in the hospitality industry: Mediating effects of sustainable competitive advantage. Sustainability, 12, 2939; doi:10.3390/su12072939.

Ibrahim, A. U., \& Daniel, C. O. (2019). Impact of leadership on organizational performance. International Journal of Business, Management and Social Research, 06, 367-374.

Jain, V. K., \& Sharma, S. (2014). Drivers affecting the green supply chain management adaptation: a review. The IUP Journal of Operations Management, 13.

Kahanaali, R. A., Khaksar, E., \& Abbaslu, L. (2015). The impact of green procurement on consequences of green supply chain management. International Journal of Operations and Logistics Management, 4, 1-13.

Keszey, T. (2020). Environmental orientation, sustainable behavior at the firm-market interface, and performance. Journal of Cleaner Production, 243, 118524. doi: 10.1016/j. jclepro.2019.118524.

Koohang, A., Paliszkiewicz, J., \& Goluchowski, J. (2017). The impact of leadership on trust, knowledge management, and organizational performance: a research model. Industrial Management \& Data Systems, $117,521-537$.

Kumar, A. (2014). Authentic leadership and psychological ownership: the investigation of interrelations. Leadership, and Organization Development Journal, 35, 266-285.

Kuria, L. K., Namusonge, G. S., \& Iravo, M. E. (2016). Effect of leadership on organizational performance in the health sector in Kenya. International Journal of Scientific and Research Publications, 6, 658-663. ISSN 2250-3153.

Lee, S., Kim, S., \& Choi, D. (2012). Green supply chain management and organizational performance. Industrial Management, and Data Systems, 112, 1148-1180.

Macmillan, H., \& Tampoe, M. (2001). Strategic management, process, content, and implementation. Oxford university, Press, UK. 
A. F. Ahmad - G. Karadas - H.F. Ahmed 13/4 (2021) 3498-3513

Madu, C. N., Kuei, C., \& Madu, I. E. (2012). A Hierarchic Metric Approach for Integration of Green Issues in Manufacturing: A Paper Recycling Application. Journal of Environmental Management, 64, 261-272.

Mastrangelo, A., Eddy, E. R., \& Lorenzet, S. J. (2014). The relationship between leadership and organizational performance. Leadership and Organization Development Journal, 35, 590-604.

McNeish, D. (2017). Thanks, coefficient alpha; we will take it from here, Psychol Methods, 23(3), 412-433.

Min, H., \& Galle, W. P. (2001). Green purchasing practices of US firms. International Journal of Production Economics, Elsevier, 21, 1222-1238.

Ottman, J. A., Stafford, E. R., \& Hartman, C. L. (2010). Avoiding Green Marketing Myopia. 76 Hilton, Ronald" Managerial Accounting, Creating Value in a Dynamic.

Prasetyo, P. E., Setyadharma, A., \& Kistanti, N. R. (2020). The role of social capital in new product development and business competitiveness enhancement. International Journal of Scientific $\mathcal{E}$ Technology Research, 9, 1838-1843.

Rao, P., \& Holt, D. (2005). Does the green supply chain lead to economic performance? International Journal of Operations and Production Management, 25, 898-916.

Rehman, S., Sami, A., Haroon, A., \& Irfan, A. (2019). Impact of sustainable leadership practices on public sector organizations: a systematic review of past decade. Journal of Public Value and Administrative Insight, 2(3), 1-5.

Sarkis, J. (2003). A Strategic Decision-Making Framework for Green Supply Chain Management. Journal of Cleaner Production, 11(4), 397-409.

Sarstedt, M., Ringle, C. M., \& Hair, J. F. (2017). Partial least squares structural equation modeling (PLS-SEM), Book Chapter, C. Homburg et al. (eds). Handbook of Market Research, Springer International Publishing AG.

Sharif, A. M., \& Irani, Z. (2012). Supply chain leadership. International Journal of Production Economics, Elsevier, 140, 57-68.

Singh, P. B., \& Pandey, K. K. (2012). Green Marketing: Policies and Practices for Sustainable Development. Integral Review: A Journal of Management, 5(1), 22-30.

Tan, C. L., Mohd, S. H., Tan, S. C., \& Shaharudin, M. R. (2016). The impact of green supply chain management practices on firm competitiveness. International Journal of Business Innovation and Research, $11,539-558$.

Tharenou, P., Donohue, R., \& Cooper, B. (2007). Management research methods; Cambridge University Press: Melbourne, Australia.

Toke, L. K., Gupta, R. C., \& Dandekar, M. (2013). Green Supply Chain Management: Practices, Performance, and Pressure within the Manufacturing Industry. Inter. Journal of Emerging Tech. in Computational and Applied Sciences (IJETCAS), 6, 122-127.

Uzcategui, S. C., Garcia, D. E., Garcia, S. O., Zaldumbide, P. D., \& Solano, S. J. (2018). Relationship of leadership, strategy, and business environment of the Ecuadorian SME competitiveness. ESPACIOS, 39, $1-10$.

Vachon, S., \& Klassen, R. D. (2008). Environmental management and manufacturing performance: The role of collaboration in the supply chain. International Journal of Production Economics, 111, 299-315.

Villanueva, R., García, J. L., \& Adame, W. (2013). Green supply chain management; a competitive advantage. International Congress on Logistics \& Supply Chain, CILOG. Sanfandila, Queretaro, Mexico. $24-25$ October.

Walumbwa, F. O., Avolio, B. J., Gardner, W. L., Wernsing, T. S., \& Peterson, S. J. (2008). Authentic leadership: Development and validation of a theory-based measure. Journal of Management, 34, 89-126. 
A. F. Ahmad - G. Karadas - H.F. Ahmed 13/4 (2021) 3498-3513

Wheelen, T. L., \& Hunger, J. D. (2011). Concepts in strategic management and business policy. Pearson Education India.

Zhu, Q., \& Sarkis, J. (2004). Relationships between operational practices and performance among early adopters of GSCM practices in Chinese manufacturing enterprises. Journal of Operations Management, 22, 265-289.

Zhu, Q., Sarkis, J., \& Geng, Y. (2005). Green supply chain management in China: pressures, practices, and performance. International Journal of Operations \& Production Management, 25, 449-468. 